\title{
Finding Opportunity in Complexity: A Case for Tackling More, Not Less, in Beginning Design Studio
}

\author{
BRIAN HOLLAND \\ University of Arkansas
}

This paper addresses the understudied educational space of what is commonly understood as the preprofessional portfolio-development studio. It describes a design pedagogy developed to serve preprofessional and non-design-major students from liberal-arts colleges pursuing admission to a first-professional graduate degree program in architecture. Starting from the premise that in complexity lies myriad opportunities for discovery and growth, this studio establishes a robust platform for this unique group of students to encounter the richness and expansiveness of the discipline, and to understand and explore architecture's capacities as an agent of positive change in the world. It is further argued that what a complex, case study-based design project facilitates for these beginning design students is a depth and richness of engagement, and that like a great work of literature, a complex architectural problem asks students to wrestle all at once with its many layers-with its clarity and contradictions, its strengths and shortcomings-and to evaluate its evolving place in, and meaning to society. In this light each student's efforts to define their own approach can be shown to reveal insights not only about the object of study, but also about themselves and their own nascent interests in design, architecture, and the built environment.

The graduate-level first professional degree in architecture is somewhat unique among advanced courses of graduate study in that students regularly come to it from a wide range of educational backgrounds and with diverse professional and life experiences. Given the breadth of subjects that an architectural education addresses, this openness is commonly understood to be one of the discipline's characteristic strengths. For a certain group of students, however, the path from an undergraduate liberal-arts education to admission into a professional graduate degree program in architecture can present certain challenges. In particular, those without backgrounds in design or visual arts must first develop a creative portfolio as a prerequisite for competitive admission to most first-professional degree graduate design programs.

This need to demonstrate design potential through a portfolio of visual and creative works constitutes for some students a transitional phase of their education and is sometimes undertaken outside of traditional institutional contexts. In recent years, the number of architecture and design schools catering to this population by offering standalone portfolio development courses has expanded in response to growing demand. ${ }^{1}$ Nevertheless, this transitional phase of an architectural education-between undergraduate and graduate studiesremains understudied by both researchers and pedagogues. The practical and economic challenges this transitional space of portfolio development poses for aspiring architecture students recommends it as an important and relevant topic of inquiry, especially in light of the ACSA Fall 2019 conference's call for the discipline to more forcefully address issues of equity and access in architecture. But it is also interesting for the particular educational opportunities it presents, and it is the lessons learned from eight years of teaching in this unique educational space-the pre-professional portfolio development studio tailored to advanced students and postgraduates of liberal-arts programs-that is the subject of this paper. ${ }^{2}$

\section{BEGINNING DESIGN STUDIO AS A PLATFORM FOR INDIVIDUAL DISCOVERY}

Urban Transformations is an introductory architectural design studio pedagogy developed to serve both pre-professional and non-design-major students from liberal-arts colleges, with potential for wider application. It comprises a semester long, student-driven design investigation tackling the strategic transformation of a complex urban project by exploring public architecture and urbanism in New York City. While responding directly to their need to develop a portfolio of creative work, it is likewise designed to build upon their undergraduate liberal arts training. Starting from the premise that in complexity lies myriad opportunities for both personal and creative discovery and growth, the Urban Transformations studio establishes a robust platform to allow this diverse group of independently motivated beginning design students to encounter the richness and expansiveness of the discipline by helping them to understand and explore on their own terms architecture's capacities as an agent of positive change in the world.

The program was created for the independent Manhattanbased Institute for Architecture and Urban Studies-NY, Inc., and refined by the author over a dozen studios there from 2011-2018, before being further adapted and tested at Sarah Lawrence College from 2017-18. (Active from 2003 to 2018, the Institute grew out of the teaching programs of the Institute for Architecture and Urban Studies (1967-1984), which was 
open to students from a consortium of liberal-arts colleges and provided an architectural education as a supplement to traditional liberal-arts studies). Students at the Institute came from a variety of colleges and backgrounds, and with different academic and professional goals in mind. Some were formally enrolled in architectural studies programs; others had little or no prior experience in architecture or design but were actively contemplating graduate studies in architecture or related fields. Urban Transformations establishes a framework for this unique and varied group of highly motivated students to explore the impact of design and space-making in an increasingly complex, urbanized society.

\section{BEGINNING WITH COMPLEXITY: A CASE STUDY APPROACH}

From the very beginning of the semester Urban Transformations takes the form of a targeted case study in which each student investigates a notable building or public urban space and explores its latent potential for transformation by design. Each student's project and topic of study are unique. Project sites are chosen to suit each student's individual interests and experience, and students' design responses to their sites are self-determined. Research plays an instrumental role in the formulation of design proposals, and the act of architectural design is framed as an act of critical and creative transformation-one that is rooted both in the world of abstract ideas and in the social and material fabric of the

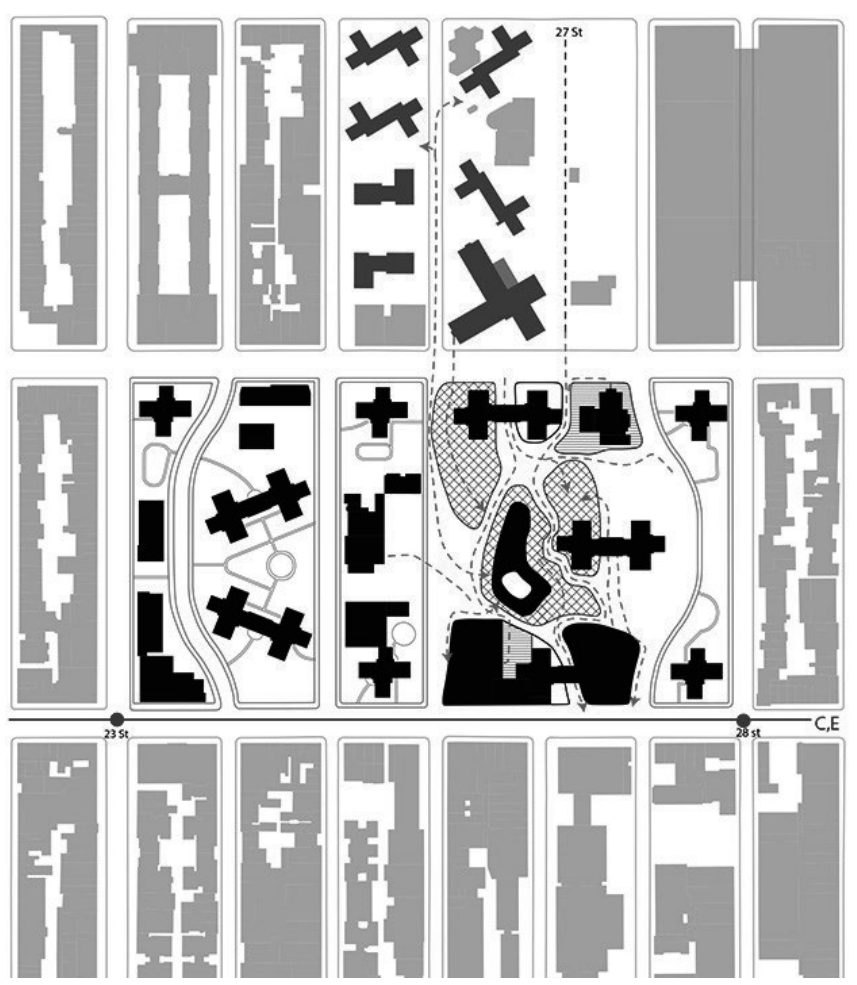

Figure 1: Site transformation study for Penn South Mutual Redevelopment Houses. Drawn by Julia Curbera. city. Over the course of the semester, students expand their understanding of the built environment while simultaneously developing their conceptual and technical abilities in design and representation.

The first half of the studio utilizes research and inquiry to drive concept generation, context definition, and skill building, so that once students reach the midpoint of the semester, they have both a clear statement of purpose about their intended design intervention, and the introductory-level skills needed to undertake it. This approach seeks to invest students in the process by which they interrogate their case study, and in the framing of their original proposals. They begin by researching their assigned site and developing an intimate understanding of its past and present conditions using maps, images, plans, models, and diagrams. From this research, they develop a historical narrative, a programmatic and spatial analysis, and a preliminary proposal for its future transformation. During the second half of the semester, students then test this proposition through an iterative architectural design process.

As case studies, the assigned projects serve a dual pedagogical role: they are both architectural design precedent and site of design intervention. They provide students with a rich context for both inquiry and action. They serve simultaneously as the social, cultural, and physical setting for student design work, and as rich historical precedent from which foundational lessons about architectural and urban design can be grasped. The case studies also serve to focus the students' explorations from the first day of studio, productively limiting the scope of their investigation, while the openness of the brief provides ample latitude for students from different backgrounds to leverage their own particular talents and interests toward unique and original ends. Given the importance of a student's first studio experience in shaping their decisions about possible career trajectories, the approach to project development remains open and flexible throughout the process. In recognizing and responding to the wide range of paths that this group of students follow along their trajectory from an undergraduate liberal arts education to graduate studies in architecture, Urban Transformations grants full agency to each individual student in shaping what is in many cases their first substantive exploration of architectural or urban design. By introducing architectural design alongside urban studies in a studio setting, the studio equips these beginning design students with the tools to engage in broad-based, critical inquiry as a means of engaging with, and designing for, the richness and complexity of the contemporary city.

Ultimately what a complex, urban project facilitates for beginning design students is a depth and richness of engagement. Like a great work of literature, it asks students to wrestle all at once with its many layers-with its clarity and contradictions, its strengths and shortcomings-and to evaluate its evolving place in, and meaning to society (past, present, and future). 

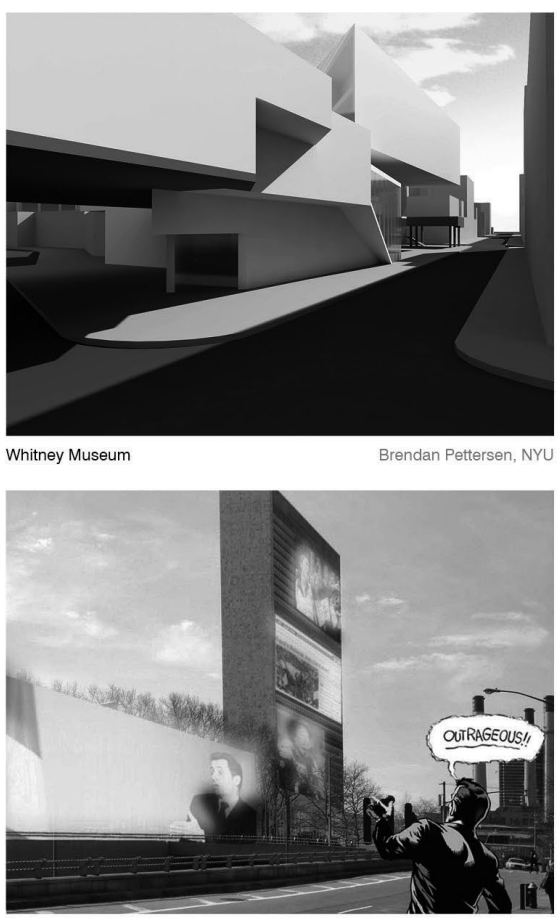

United Nations Camilo Espitia, Florida Atlantic University

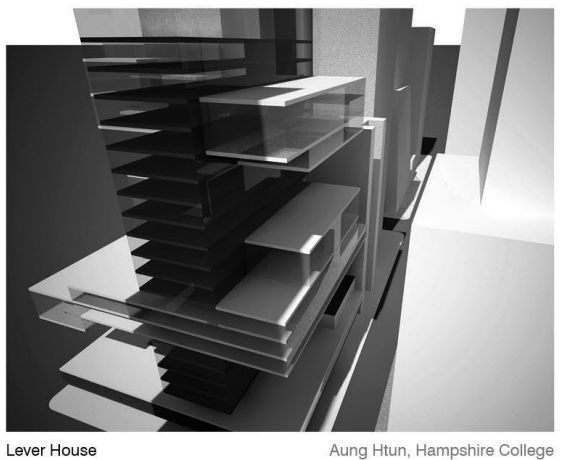

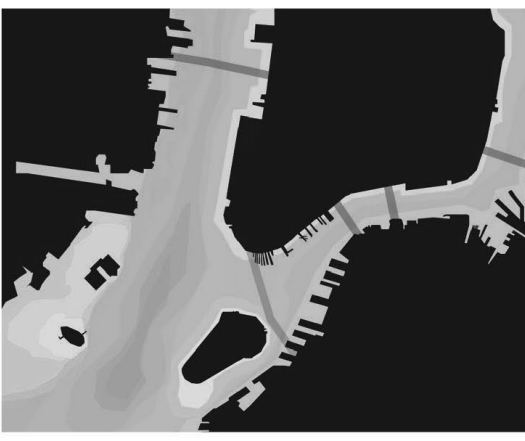

Mali Bowers, NYU Gallatin

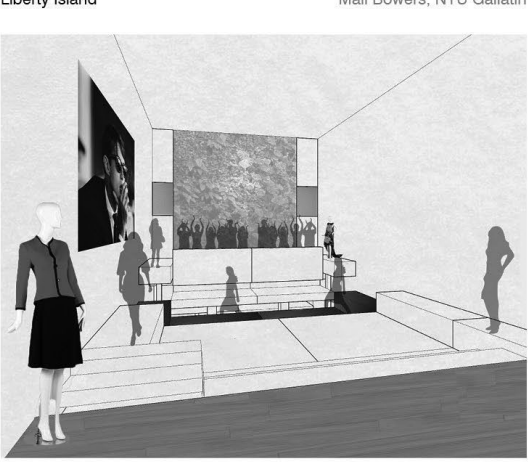

Paul Rudolph's Halston House Julia McConnell, Mount Holyoke College

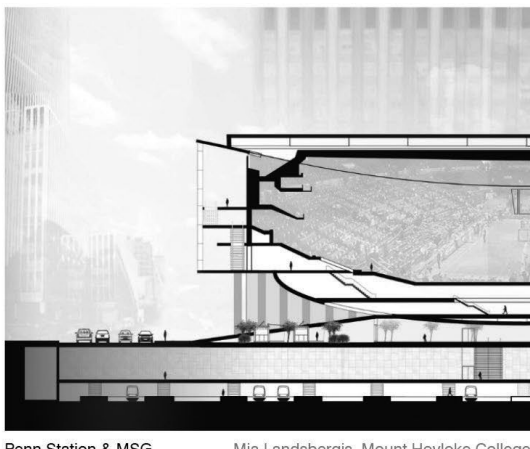

Penn Station \& MSG

Mia Landsbergis, Mount Hoyloke College
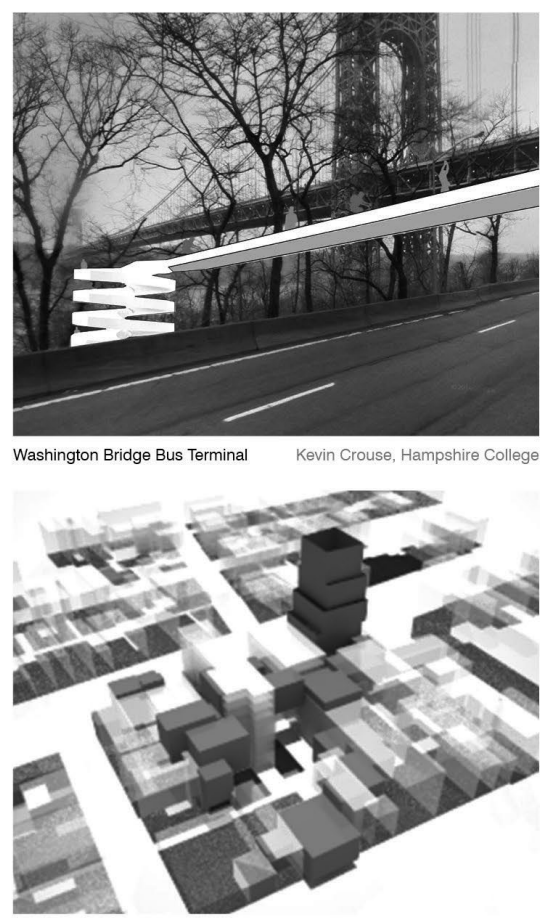

Irene Li, NYU

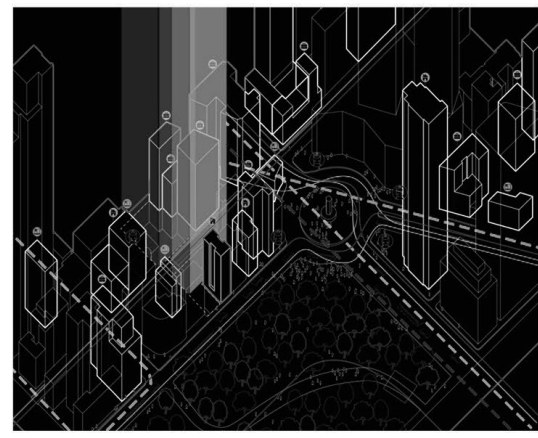

Columbus Circle

Figure 2: Representative design work from the Urban Transformations studio. Participating students came from a variety of colleges and backgrounds, and with different academic and professional goals in mind. Urban Transformations establishes a framework for this unique and varied group of highly motivated students to explore the impact of design and space-making in an increasingly complex, urbanized society.

Students come to recognize that to work with the built environment-especially in challenging urban environments-is to work with and within many contexts simultaneously. The task of the beginning design student is surely not to be comprehensive in this effort, but to find their own way to engage. Through this approach, students also learn to acknowledge that such a project is not graspable (or easily summarized) in a single, tidy paragraph. Urban projects have many complex layers, and each student's unique efforts to define their own approach will in some ways reveal insights not only about the object of study, but also inevitably about themselves, and their own nascent interests in design, architecture, and the built environment.

What follows is a detailed description of the Urban Transformations studio and several examples of work produced by students in the program under the author's instruction.

\section{PART ONE: INVESTIGATION AND DISCOVERY}

In the first phase of the studio the chosen case studies serve as stimulants for design inquiry as students construct a richly developed context for their work. Students do this by way of a three-part mixed-method research endeavor. They investigate their assigned project's history and construct a narrative timeline (historical inquiry); they study its spatial logics through the careful examination of maps, plans, sections, models, and other forms of architectural documentation (design process investigation); and they conduct field observations to obtain first-hand knowledge of their project's subjective qualities and patterns of use (empirical inquiry). Students conduct these investigations simultaneously so that questions and insights from one method of inquiry may inform the others, thereby strengthening the overall investigation through positive feedback loops. 

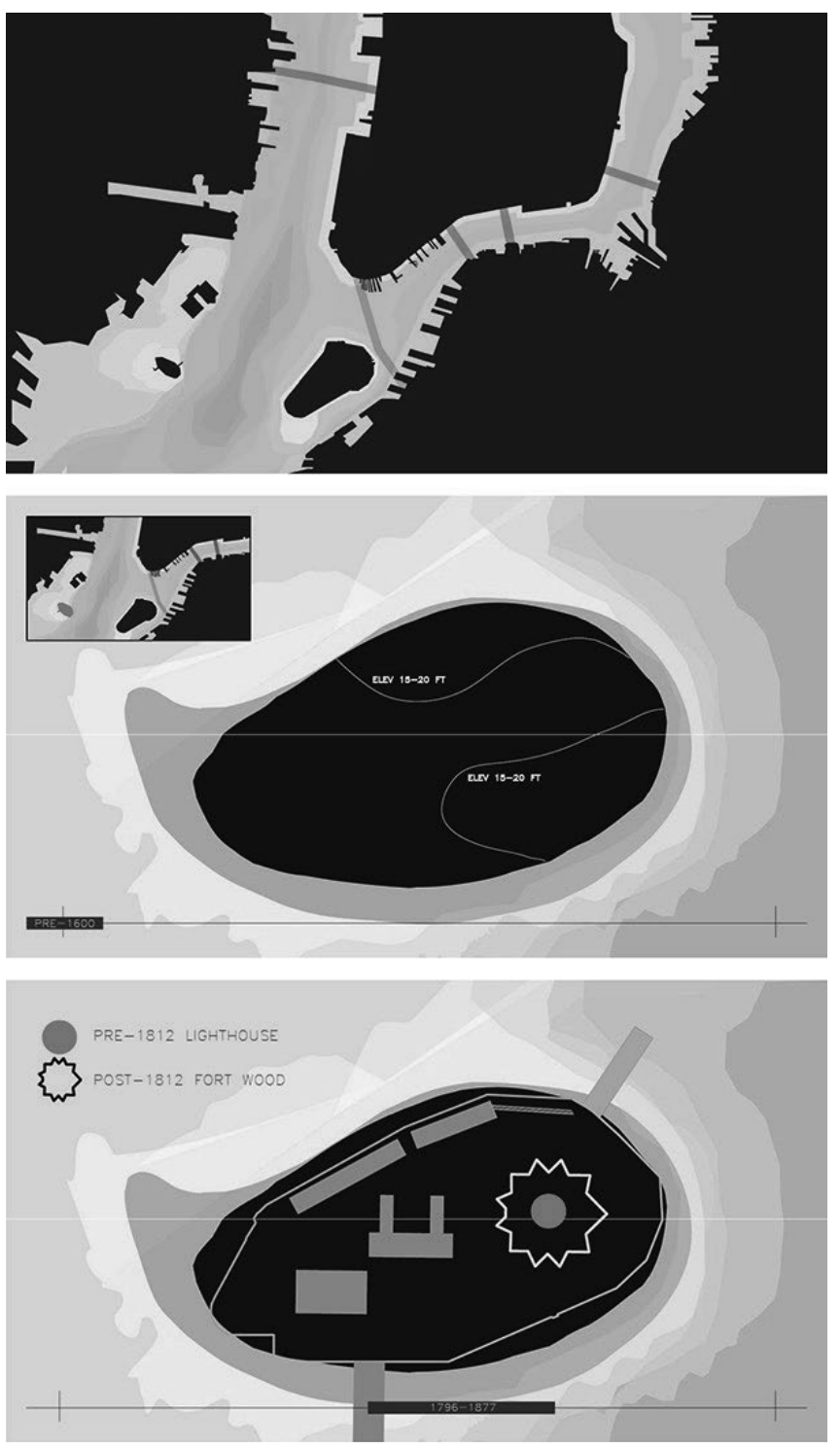

Figure 3: Historical development timeline for Liberty Island. Drawn by Mali Bowers, a student from NYU's Gallatin School of Individualized Study.

Project Narrative (historical inquiry): Students begin their investigation by researching their assigned building or public space. They are asked to construct a narrative delineating the project's social, cultural, and architectural histories by considering the following questions: When was the current project conceived, designed, and/or built, and by whom? What are its uses (programs, activities)? What preceded this project-what motivated its creation, and what subsequent transformations has it undergone? Students are encouraged to consider their site's history as both a physical place and a cultural entity: Was it always located on its present site? Did it have earlier incarnations? If hosting an institution-was it located elsewhere previously, and how has it changed over time? By whom was it designed, and what design theories or planning concepts informed its development? Studio discussions emphasize ways that buildings and urban spaces are valued and assessed differently by different people, and students are asked to collect images, narratives, and descriptions from different sources to reflect that diversity.

Throughout this phase of the studio, readings and instructional support equip students with both the conceptual and practical scaffolding to successfully undertake these investigations. Readings from Georges Perec's Species of Spaces prompt further reflection on the social and cultural inhabitation of space at different scales, and concepts and methods for direct observation and notation in the field. A close reading of the innovative graphic novel Here by Richard McGuire facilitates discussion of techniques for representing narrative using both spatial and historical frames, and the continuities and discontinuities of cultural and material transformations in the built environment. 05

A series of presentations on architectural representation along with software instruction (Rhino, Abode Photoshop, Illustrator, and InDesign) help students ground theoretical development with a foundation of practical training. Students organize their findings into a digital presentation at the end of the first week of work and continue developing and refining this narrative as the semester progresses.

Architectural Documentation (design process investigation): Alongside their work on narrative histories, students are tasked with developing a rich spatial understanding of their project in its current state. They begin by searching for architectural documentation, and are tasked with acquiring as many useful images, maps, drawings, diagrams, and details as possible.

Through this effort students develop useful skills for obtaining high quality visual documentation of buildings and urban spaces from a variety of archival sources. Since the quality of the found material is variable, students are exposed to digital image-editing software which they use to prepare materials for use in presentations and in a digital drafting environment. They then incorporate this material into their narrative presentation, expanding and supporting their historical description of the project with a spatial one.

Using the existing project documents as an underlay, students create a plan, site plan, and site sections for their assigned project. They learn to construct measured orthographic drawings in the computer, locating their project in its immediate urban context. The goal is for students to learn to use these drawings as tools to understand and analyze relationships between their project and the city.

Field Observation (empirical inquiry): The third component of students' research involves visiting their sites to experience project spaces and user activities firsthand, and to record their observations. They learn to conduct field observation 


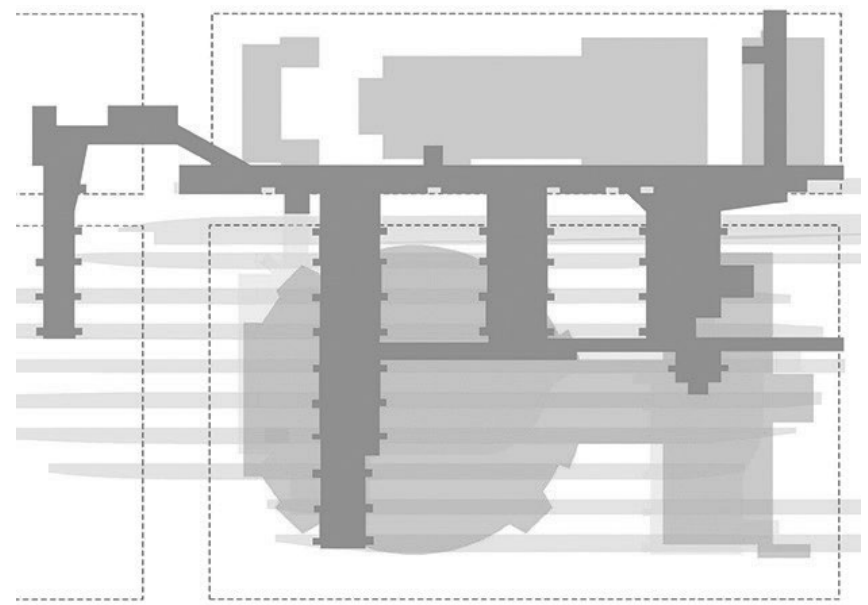

Figure 4: Site plan for Penn Station and Madison Square Garden. Drawn by Emilija Landsbergis, an architectural studies student from Mount Holyoke College.

and research, and to create graphic systems of notation to document their findings. Students learn to describe urban space through the representation of built form, human activity, and environmental phenomena. They learn techniques for representing related graphic information across drawings of different scale. Readings from Georges Perec's Species of Spaces and William Whyte's The Social Life of Small Urban Spaces support this effort, stimulating discussions on methods for observing the everyday at different scales, and for developing personal systems of notation. 06

Before visiting their site in person, they are encouraged to study it online via Google Earth and Street View. During their visit students photograph their site, sketch, and take detailed notes. They are asked to pay attention to the project's architectural qualities as well as its context and use, and to carefully observe how people interact with the space.
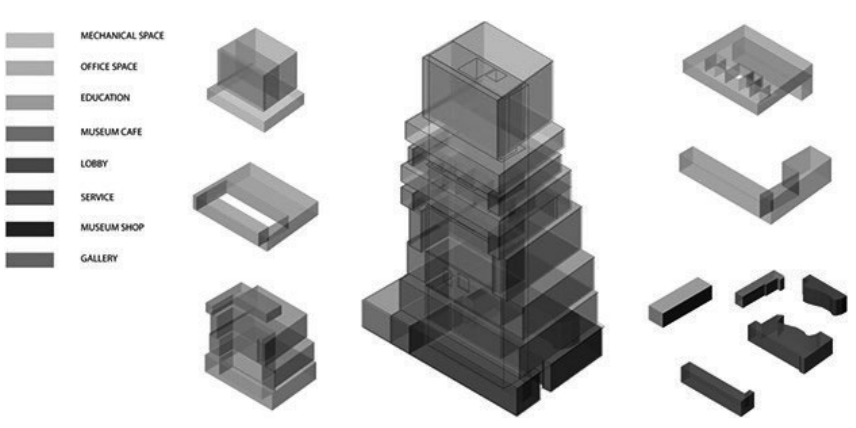

Figure 5: Analytical diagram for the New Museum. Drawn by Haoning $\mathrm{Li}$, a student from New York University.
During their site visit, students are asked to map entrances and exits to and through their project. They are challenged to move beyond casual observation by looking closely, asking themselves why things are the way they are. They are encouraged to consider this as architectural detective work. What details are of particular interest? Students devise a graphic system of notation for recording their observations on their found site plan and/or section. As with their historical research, the nature of their observations is guided by their own individual interests and attention, and by the contingencies of the project at hand.

Lastly, students develop a digital presentation of their findings, integrating their direct observations with the historical narrative and architectural documentation.

\section{PART TWO: ANALYSIS AND TRANSFORMATION}

After developing a historical narrative of their site's transformation over time, documenting its formal and spatial makeup through architectural drawings and models, and recording their initial field observations, students then undertake a three-part program of contextual analysis.

\section{Design Precedent Analysis}

Students begin their analysis by critically evaluating the project's design in light of the project narrative. By examining the project in relation to its design historical context, they begin to learn how to relate the built environment to the history of ideas. It is in this sense-as design precedent-that their case study constitutes a vehicle for exposing students to architectural and urban design histories; for placing these design histories in a social, cultural, and/or environmental context, and for beginning to develop a base of architectural knowledge.

Alongside the study of their project's historical and theoretical basis, students undertake a careful analysis of its architectural composition. Through digital drawing and modeling, as well as analytical diagramming, they begin to engage with concepts of space, form, circulation, typology, and program, among other issues unique to each individual project. In learning to both read and construct these diagrams, students develop abilities to read and understand built form.

\section{Site Analysis}

Using the plans and sections generated in the first phase of work as underlays, students explore techniques for 


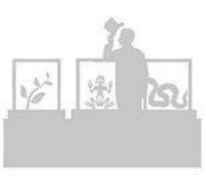

Victorian

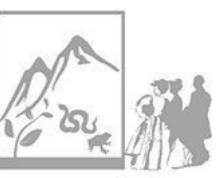

Modern

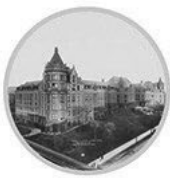

Victorian Gothic and Richardsonian 1877-1908

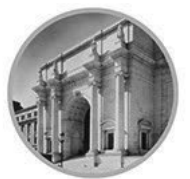

Beaux-Arts and Moderne 1916-1934

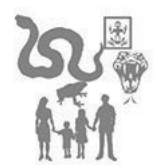

Postmodern

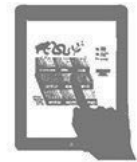

Contemporary

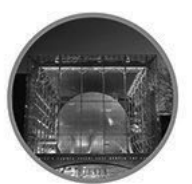

Postmodern and New Classical 1992-2000

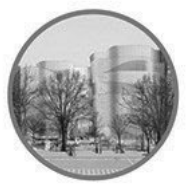

Contemporary 2019
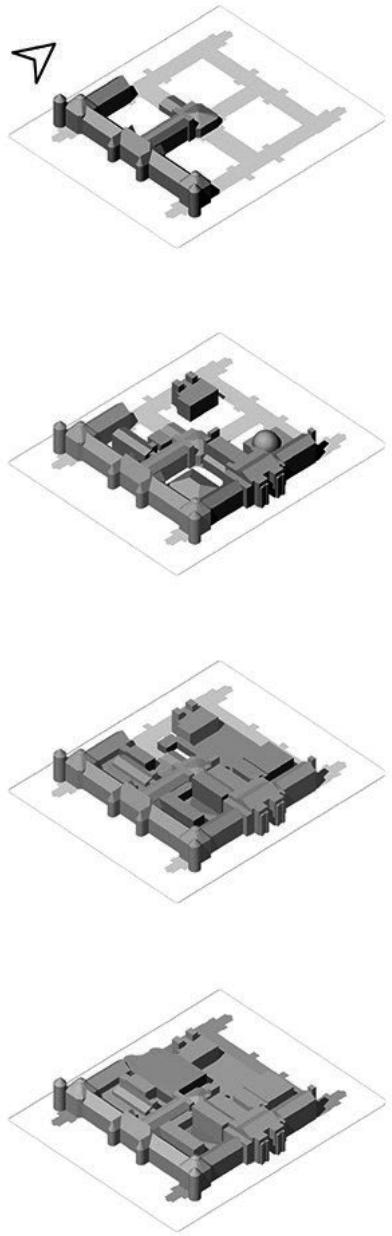

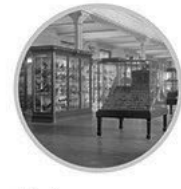

Vitrine

1870-Present

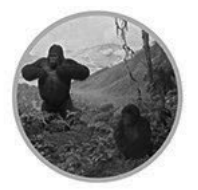

Diorama

1909-Present

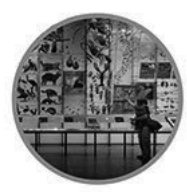

Edutainment 1970-Present

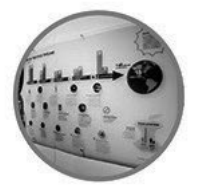

Infographic 2005-Present
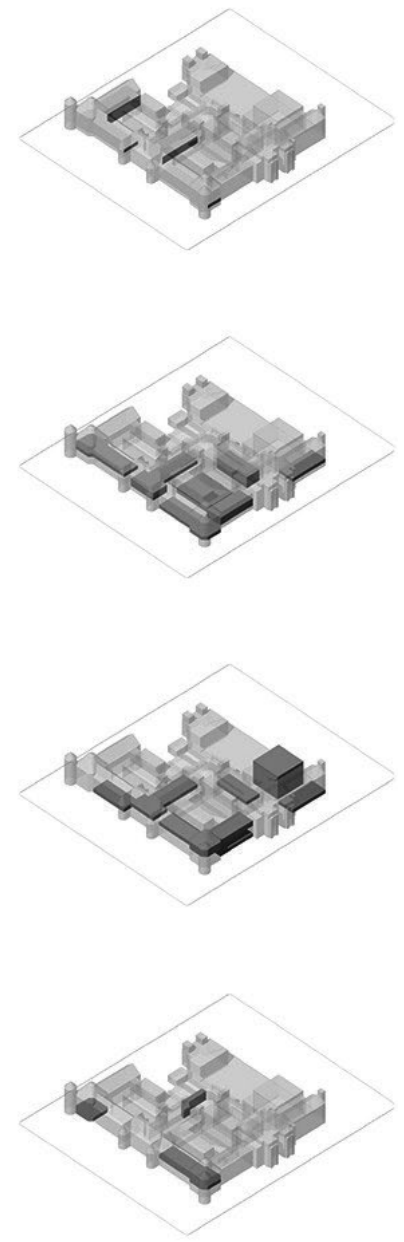

Figure 6: Historical Analysis of architecture and exhibition at the American Museum of Natural History. Project by Nicholas Miller, a student in urban design and architecture studies from New York University.

incorporating the most promising data gathered from their field observations to a create a series of analytical site drawings. This exercise introduces techniques for recording and mapping observations of the built environment, introduces and builds architectural skills such as drawing, modeling, and diagramming (circulation, program, light, density, etc), and introduces techniques for recording and mapping direct observations. Data gathering through G.I.S. tools are also explored to extend students' readings of site beyond the spatial and physical to include layers of social, historical, and environmental information.

\section{Narrative Critique}

Curious, critical, and systematic inquiry forms the foundation of this approach. Students learn to see research as a precondition of informed design. They learn the value of looking closely and asking critical questions about what they see and don't see in the buildings and urban spaces around them; to ask why things are the way they are and to imagine them otherwise.

Students are asked to synthesize their research findings by constructing a range of contextual frames highlighting their project's social, cultural, and/or environmental makeup. For instance, they evaluate the project's history in light of their field observations and ask how the project might be changed or improved in response to the shortcomings of the original design, or changes in society or technology. They search for evidence of obsolescence, contradictions, disjunction, or misalignments between the project's original ambitions and its present state. Students ask how the project might continue to change in the future in relation to social or environmental 


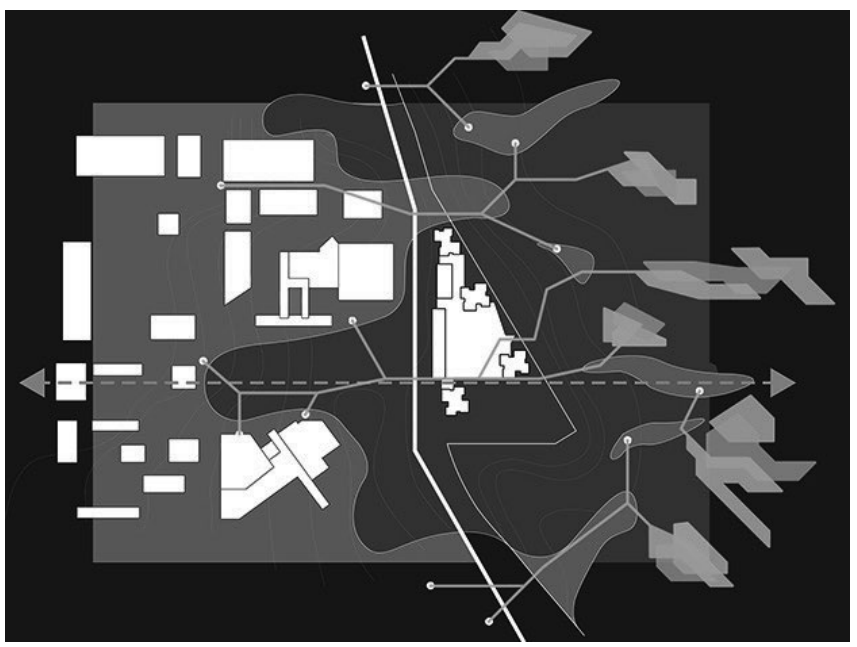

Figure 7: Transformation study for Manhattan's Waterside Plaza. Here the plaza's linear bulkhead is 'thickened,' bringing floodable parks inland, and newly inhabitable islands, peninsulas, and piers out into the East River to both dissipate wave energies and challenge the city's residents to venture beyond the water's edge. Project by Henry Wang

needs, how might changing cultural narratives alter its role in the city, and how might design intervene in this process?

\section{Transformation Diagrams}

Based on their reading of the project, and in response to the particular context they have framed for it, students begin to explore possible strategies for transformation. These could be spatial, social, programmatic, and/or formal interventions. In all cases, students are challenged to consider how they might intervene in the project's existing logics, and to what end. Students document their thought processes with drawings and diagrams. The goal at this stage is not to redesign the architecture itself, but to reconfigure the relationships described within its diagrammatic representations.

For the midterm review, students develop a graphic presentation to include site research and analysis in the form of a historical narrative; site research and analysis in the form of architectural drawings, models, and diagrams; and their preliminary proposal for transformation, represented graphically and narratively. Reviews take the form of a linear narrative in order to help students learn that design is fundamentally a value proposition, and that the designer inhabits a dual role as both agent and advocate. By structuring their presentation in the form of a linear narrative, and supporting their argument with stories, images, drawings, and diagrams, they come to learn that they are entering into an ongoing conversation about the collective interpretation of the city's past and present conditions and staking their claim for a piece of its future.

Transformation Studies

For the rest of the term students test these diagrammatic proposals through iterative design explorations. The method of design is inevitably unique to each student and each project, based on the nature of their proposal. Generally, they are asked to expand on their earlier analyses and begin by conducting formal and/or spatial transformation studies. After refining their original diagrams and drawings based on the midterm critique, they are then challenged to consider how these diagrams change in light of their intended transformations. Students document their approach by diagramming their thinking and working process and maintaining a consistent system of notation and graphic representation.

Finally, once students have developed a clear diagrammatic approach to transformation in both $2 \mathrm{D}$ and $3 \mathrm{D}$, they are asked to consider how their new diagrams might have spatial

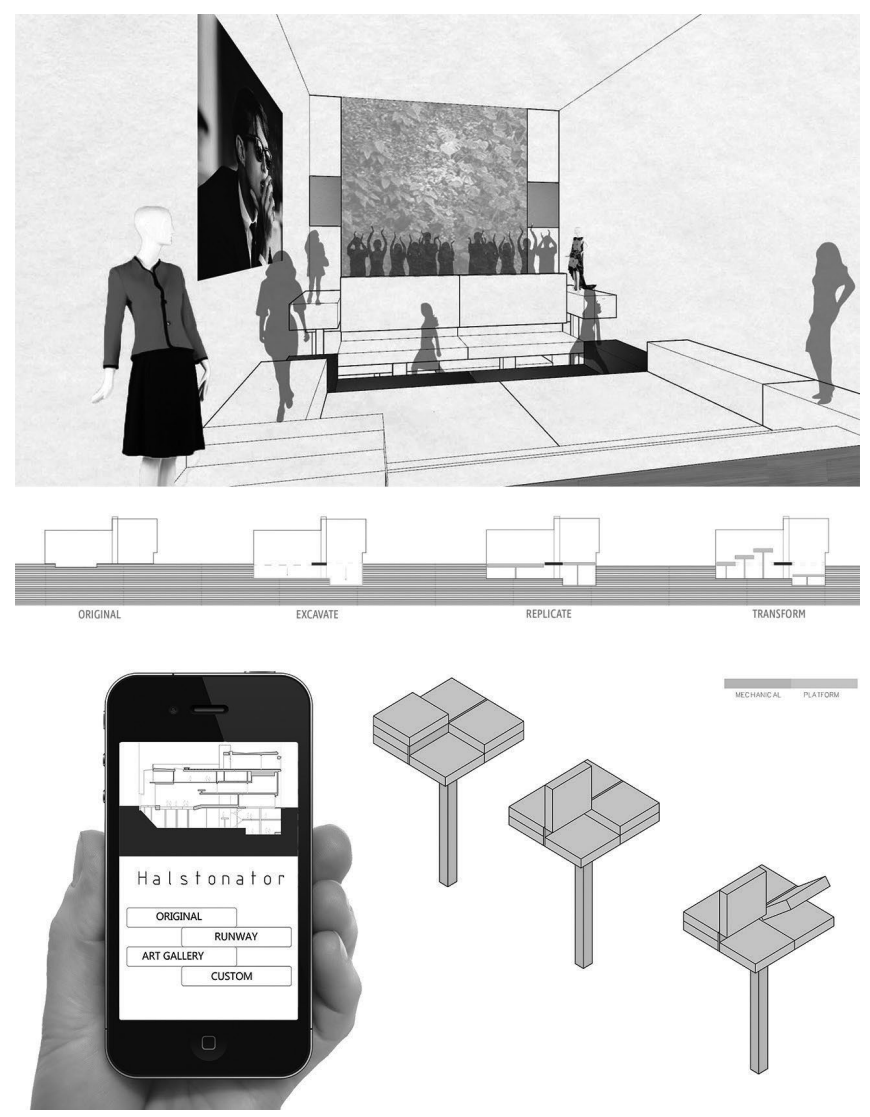

Figure 8: A proposal for Paul Rudolph's townhouse at 101 East 63rd St. Project by Julia McConnell from Mount Holyoke College. 

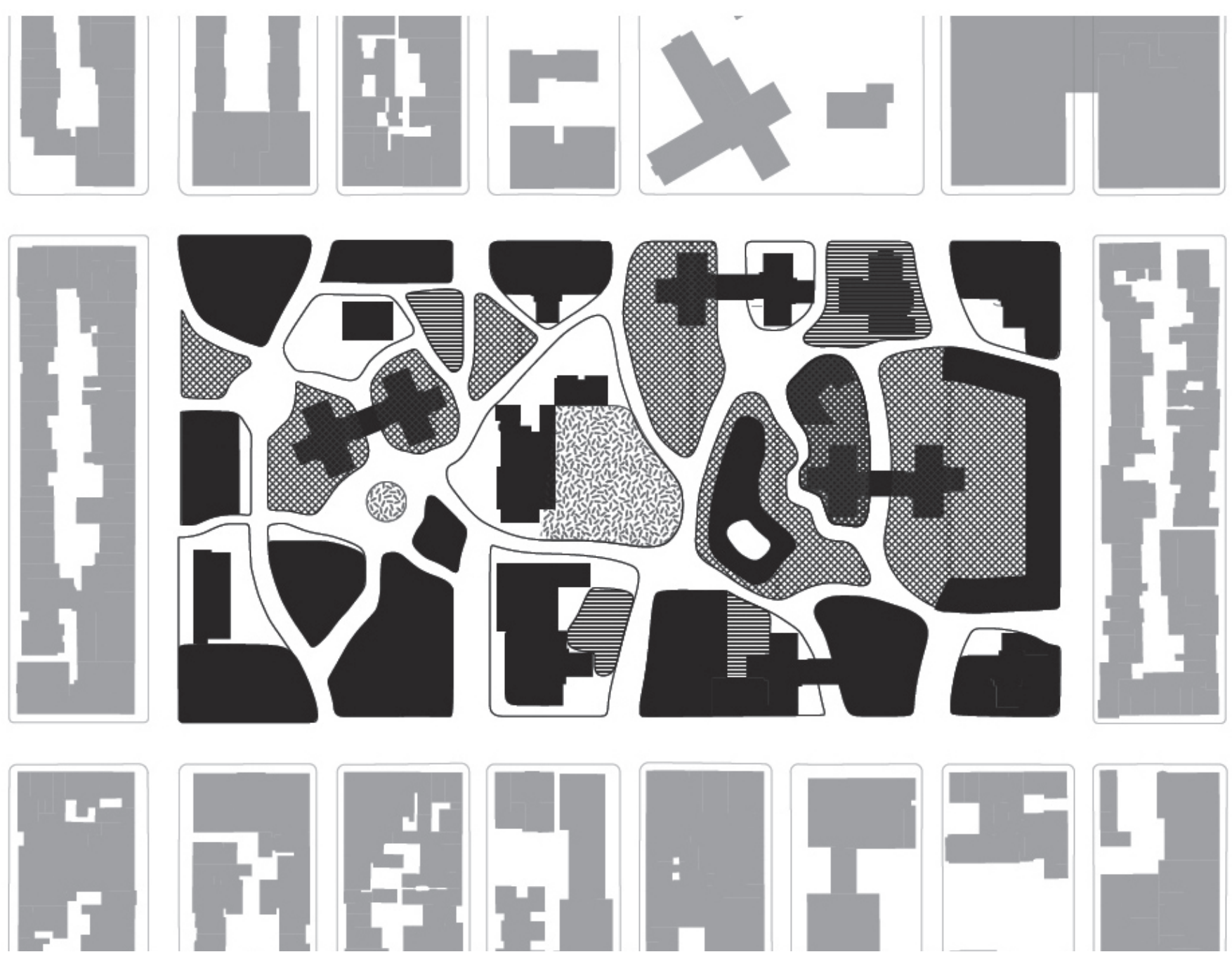

Figure 9: Transformation study for Penn South Mutual Redevelopment Houses. This student sought to preserve and expand Penn South's affordability far into the future. In the face of coming demographic changes, she developed a menu of variable phasing strategies to both densify and diversify the project, while simultaneously expanding existing programmatic networks and strengthening community solidarity. Project by Julia Curbera.

implications or suggest physical form. They use their method of analysis to direct their method of design, and they continue developing their digital model through the final weeks of the semester. In addition to studying their transformations in both plan and section, students are asked to document this process rigorously, and to develop a set of conceptual and analytical diagrams that explain their proposals.

Upon finalizing their transformation studies, students again develop a graphic presentation to include their historical narrative, as well as their architectural drawings, models, and diagrams. They are asked to reflect upon their original ambitions for the project's transformation, and to evaluate these in light of their transformation studies. Did their initial ideas or expectations change during the design process? Did newly discovered constraints challenge their original assumptions, or did unexpected opportunities surface along the way, prompting a reevaluation of their earlier ambitions?

\section{DESIGN AS TRANSFORMATION}

The act of building is commonly equated with the creation of something new in the world; herein lies architecture's agency as may be commonly understood-an additive agency, or, as the Modernists understood it, architecture as the replacement or remaking of the world. Increasingly, as the built environment in North America has become denser and more built up, it has been argued that architects can and should explore the transformative possibilities of an architecture that operates primarily as an open-ended process of adaptation or 
alteration. Some even argue that the architect's agency may increasingly lie in strategic acts of unbuilding.08

Considered in this light, architecture's engagement with the world can be tested through the transformation of given structures, patterns, relationships, and institutions, rather than the embodiment of new ones created from whole cloth. The Urban Transformations studio pedagogy develops architecture's transformative logics both in an effort to prepare students to address the changing nature of the world for which they will build (and unbuild), and to attune them to the important role that context can play in their design work.

\section{Acknowledgments}

The author would like to acknowledge Kevin Kennon, founder and Executive Director of the Institute, for his steadfast vision in creating and maintaining a supportive environment for a group of uniquely motivated students to take creative and intellectual risks in the cause of exploration and self-discovery. Gratitude is also due to the faculty of the Visual Arts Department at Sarah Lawrence College for granting the author the opportunity to explore this approach as a visiting faculty member during the 2017-18 academic year.

Finally, the author would also like to thank Julia McConnell and Nick Miller for a series of inspired (and inspiring) conversations reflecting upon their experiences as students in the Urban Transformations Studio, and for their participation in the development and presentation of this paper's content at the ACSA 2019 Fall Conference in Stanford.

\section{ENDNOTES}

1. The author's preliminary, anecdotal inquiries suggest that many if not most students in this circumstance currently enrolled in M. Arch programs at some of the top-ranked programs in the United States had previously attended one or more portfolio development courses prior to applying to graduate school, and most of these had attended such courses at one of a small number of elite institutions.

2. The description of the Urban Transformations studio draws from a paper that was accepted, but never presented as part of the following conference: Holland, Brian, "Architecture in the World: The Study and Transformation of Context in Beginning Design Studio" in National Conference on the Beginning Design Studio, 2019. 